\title{
Effects of $\beta$-alanine supplementation on exercise performance: a meta-analysis
}

\author{
R. M. Hobson • B. Saunders • G. Ball • \\ R. C. Harris $\cdot$ C. Sale
}

Received: 21 October 2011/ Accepted: 9 December 2011/Published online: 24 January 2012

(C) The Author(s) 2012. This article is published with open access at Springerlink.com

\begin{abstract}
Due to the well-defined role of $\beta$-alanine as a substrate of carnosine (a major contributor to $\mathrm{H}^{+}$buffering during high-intensity exercise), $\beta$-alanine is fast becoming a popular ergogenic aid to sports performance. There have been several recent qualitative review articles published on the topic, and here we present a preliminary quantitative review of the literature through a meta-analysis. A comprehensive search of the literature was employed to identify all studies suitable for inclusion in the analysis; strict exclusion criteria were also applied. Fifteen published manuscripts were included in the analysis, which reported the results of 57 measures within 23 exercise tests, using 18 supplementation regimes and a total of 360 participants [174, $\beta$-alanine supplementation group (BA) and 186, placebo supplementation group $(\mathrm{Pla})]$. BA improved $(P=0.002)$ the outcome of exercise measures to a greater extent than Pla [median effect size (IQR): BA 0.374 (0.140-0.747), Pla 0.108 $(-0.019$ to 0.487$)]$. Some of that effect might be explained by the improvement $(P=0.013)$ in exercise capacity with BA compared to Pla; no improvement was seen for exercise performance $(P=0.204)$. In line with the purported mechanisms for an ergogenic effect of $\beta$-alanine supplementation, exercise lasting 60-240 s was improved $(P=0.001)$ in BA compared to Pla, as was exercise of $>240 \mathrm{~s}(P=0.046)$. In contrast, there was no benefit of $\beta$-alanine on exercise lasting $<60 \mathrm{~s}(P=0.312)$. The median effect of $\beta$-alanine supplementation is a $2.85 \%(-0.37$ to $10.49 \%)$ improvement in
\end{abstract}

R. M. Hobson · B. Saunders · G. Ball · C. Sale $(\bowtie)$ Biomedical, Life and Health Sciences Research Centre, School of Science and Technology, Nottingham Trent University, Clifton Lane, Nottingham NG11 8NS, UK e-mail: craig.sale@ntu.ac.uk

R. C. Harris

Junipa Ltd, Newmarket, Suffolk, UK the outcome of an exercise measure, when a median total of $179 \mathrm{~g}$ of $\beta$-alanine is supplemented.

Keywords $\beta$-Alanine supplementation - Meta-analysis . Exercise test and duration

\section{Introduction}

Anaerobic glycolysis is the dominant energy source during high-intensity exercise. As exercise progresses, the hydrogen ions $\left(\mathrm{H}^{+}\right)$that are produced when lactic acid disassociates to lactate overcome the intracellular buffering capacity and the $\mathrm{pH}$ of the muscle falls. The lowest muscle $\mathrm{pH}$, and therefore maximum $\mathrm{H}^{+}$accumulation, occurs after approximately 4 min of high-intensity exercise (Osnes and Hermansen 1972), although others have suggested that $\mathrm{H}^{+}$ accumulation is unlikely to be the primary cause of fatigue during short duration $(<30 \mathrm{~s})$ maximal exercise (Bogdanis et al. 1998). Nonetheless, acidosis interferes with several metabolic processes that will result in reduced force production and fatigue (Spriet et al. 1989). More specifically, the accumulation of $\mathrm{H}^{+}$in the muscle has been shown to disrupt the resynthesis of phosphorylcreatine (Harris et al. 1976), inhibit glycolysis (Trivedi and Daniforth 1966) and disrupt the functioning of the muscle contractile machinery directly (Donaldson and Hermansen 1978; Fabiato and Fabiato 1978). More recent evidence also points to an effect of $\mathrm{H}^{+}$accumulation in the blood on the perception of effort during high-intensity intermittent exercise (Price and Moss 2007), which could also contribute to fatigue indirectly.

Physicochemical buffers in the muscle, of which carnosine is one, provide the first line of defence against local changes in $\mathrm{pH}$. As such, any means of increasing the ability 
of the muscle to buffer the $\mathrm{H}^{+}$, produced during highintensity exercise, is likely to be of value to athletes and athletic individuals. $\beta$-alanine is the rate limiting precursor to the synthesis of carnosine within muscle fibres $(\mathrm{Ng}$ and Marshall 1978; Skaper et al. 1973). Carnosine is a cytoplasmic dipeptide, which plays a role in the intracellular buffering of $\mathrm{H}^{+}$due to its imidazole ring having a $\mathrm{pKa}$ of 6.83 and its high concentration $(16.0 \pm 7.2$ to $29.2 \pm 2.6$ mmol kg ${ }^{-1} \mathrm{dm}$ ) within human skeletal muscle (Bate-Smith 1938; Harris et al. 1990; Dang et al. 2006). Further support for the buffering role of carnosine in skeletal muscle comes from the higher concentrations found in fast-twitch muscle fibres (Harris et al. 1998), which experience the greatest levels of $\mathrm{H}^{+}$accumulation during extreme physical work. In isolated muscle, the absence of carnosine as a buffering agent leads to fatigue due to acidification, which does not occur when carnosine is present in the surrounding medium (Severin et al. 1953).

Since muscle acidosis is likely to contribute to the onset of fatigue during high-intensity exercise, increasing the muscle carnosine concentration would theoretically increase the intracellular buffering capacity, thereby potentially delaying the onset of fatigue. Indeed, supplementation with $\beta$-alanine has been shown to significantly elevate carnosine levels in both type I and type II human muscle fibres of the vastus lateralis (Harris et al. 2006), as well as in the tibialis anterior, soleus and gastrocnemius (Derave et al. 2007; Baguet et al. 2009; Baguet et al. 2010a). This provides the rationale for the ergogenic role of $\beta$-alanine supplementation on exercise that induces $\mathrm{H}^{+}$ formation and muscle acidosis.

This ergogenic effect of $\beta$-alanine supplementation on high-intensity exercise performance in humans has led to an expansion of the commercial market for $\beta$-alanine in recent years. There has also been a concomitant increase in interest in this research area, so much so that, since the first publication on the topic by Harris et al. (2006), there are now several comprehensive qualitative reviews on the topic of $\beta$-alanine supplementation and exercise (e.g., Artioli et al. 2010; Derave et al. 2010; Sale et al. 2010).

While these reviews are undoubtedly a useful way to synthesise the available literature, such literature can also be analysed collectively in a quantitative way through meta-analysis. As such, the primary aim of this metaanalysis was to analyse the literature available on the ergogenic effect of $\beta$-alanine supplementation on exercise. The secondary aim was to investigate the outcome of the different exercise protocols employed, i.e., exercise performance and exercise capacity tests, and exercise of varying duration. This meta-analysis did not attempt to conduct a traditional qualitative review concurrently with the quantitative data presented here, and therefore readers are directed to the traditional review articles referenced above for details of the studies included in this metaanalysis.

\section{Methods}

Literature review and study selection

The published literature was searched using the databases of PUBMED, SPORTDiscus and GoogleScholar in July 2011. A variety of combinations of words and terms were entered for the search including, but not limited to, 'betaalanine', ' $\beta$-alanine', 'Beta Alanine', 'muscle carnosine', 'muscles', 'carnosine', 'buffering', 'exercise', 'training' and 'physical activity'. Hand searches of journal articles and of the reference lists from relevant publications were also performed to ensure, as far as practically possible, that all appropriate studies were considered for inclusion.

Once all relevant articles had been located, three researchers individually considered each article for its appropriateness for inclusion based on the pre-determined inclusion criteria discussed below. Where conflict in opinion arose the majority ruled on the inclusion or exclusion of the article. Several other desirable characteristics of studies were also discussed, such as the homogeneity of the participant population and the availability of information on the reliability of the exercise tests and measures employed, however, the inclusion criteria remained as they were.

\section{Inclusion/exclusion criteria}

This analysis was limited to manuscripts using human participants in placebo controlled, double blinded trials, published in English language peer reviewed journals, and which had a $\beta$-alanine only supplementation group (BA) and a placebo group (Pla). Summary details of the studies included in the meta-analysis are listed in Table 1. Due to these inclusion criteria, several studies were excluded from the analysis, for a multitude of reasons. These included those with no $\beta$-alanine only experimental group (Hoffman et al. 2006, which split participants into placebo, creatine and creatine with $\beta$-alanine groups), no exercise performance or capacity test (Smith et al. 2009b; Baguet et al. 2010b), an inappropriate testing strategy (Hoffman et al. 2008a; took baseline measurements 3 weeks after supplementation of $\beta$-alanine had commenced) or supplementation strategy (Hoffman et al. 2008b; used a cross-over study design with an insufficient wash out period), not published in peer reviewed journals (e.g., Hill 2007 and other PhD theses), or the many experiments that seem only to be available as abstracts. 
Table 1 A summary of the studies included in the meta-analysis

\begin{tabular}{|c|c|c|c|c|c|}
\hline Reference & Participants & Exercise protocol & Supplementation protocol & $\begin{array}{l}\text { Total } \\
\text { dosage }(g)\end{array}$ & $\begin{array}{l}\text { Effect sizeof all } \\
\text { measures } \\
\text { Median (range) }\end{array}$ \\
\hline $\begin{array}{l}\text { Baguet et al. } \\
\text { 2010a }\end{array}$ & $\begin{array}{l}\text { Elite rowers } \\
8 \mathrm{BA} \\
9 \mathrm{Pla}\end{array}$ & $2000 \mathrm{~m}$ rowing & $5 \mathrm{~g} \mathrm{~d}^{-1}$ for 49 days & 245 & $\begin{array}{l}\mathrm{BA}=0.261 \\
\mathrm{Pla}=-0.098\end{array}$ \\
\hline Derave et al. 2007 & $\begin{array}{l}\text { Male } 400 \mathrm{~m} \text { runners } \\
8 \mathrm{BA} \\
7 \mathrm{Pla}\end{array}$ & $\begin{array}{l}\text { Sprint running } \\
\text { Isometric endurance }\end{array}$ & $\begin{array}{l}2.4 \mathrm{~g} \mathrm{~d}^{-1} \text { for } 4 \text { days, then } \\
3.6 \mathrm{~g} \mathrm{~d}^{-1} \text { for } 4 \text { days, then } \\
4.8 \mathrm{~g} \mathrm{~d}^{-1} \text { for } 20-27 \text { days }\end{array}$ & $\begin{array}{l}\text { Up to } \\
153.6\end{array}$ & $\begin{array}{l}\mathrm{BA}=0.369 \\
\quad(0.356-0.381) \\
\mathrm{Pla}=0.284 \\
(0.253-0.315)\end{array}$ \\
\hline $\begin{array}{l}\text { Hill et al. } 2007 \\
\text { (4w) }\end{array}$ & $\begin{array}{l}\text { Recreational males } \\
13 \mathrm{BA} \\
12 \mathrm{Pla}\end{array}$ & $\begin{array}{l}\text { Cycle capacity at } 110 \% \\
\text { power }_{\max }\end{array}$ & $\begin{array}{l}4.0 \mathrm{~g} \mathrm{~d}^{-1} \text { for } 7 \text { days, then } \\
4.8 \mathrm{~g} \mathrm{~d}^{-1} \text { for } 7 \text { days, then } \\
5.6 \mathrm{~g} \mathrm{~d}^{-1} \text { for } 7 \text { days, then } \\
6.4 \mathrm{~g} \mathrm{~d}^{-1} \text { for } 7 \text { days }\end{array}$ & 145.6 & $\begin{array}{l}\mathrm{BA}=0.850 \\
\quad(0.720-0.980) \\
\mathrm{Pla}=0.043 \\
\quad(0.012-0.074)\end{array}$ \\
\hline $\begin{array}{l}\text { Hill et al. } 2007 \\
(10 \mathrm{w})\end{array}$ & $\begin{array}{l}\text { Recreational males } \\
7 \mathrm{BA} \\
8 \mathrm{Pla}\end{array}$ & $\begin{array}{l}\text { Cycle capacity at } 110 \% \\
\text { power }_{\max }\end{array}$ & $\begin{array}{l}4.0 \mathrm{~g} \mathrm{~d}^{-1} \text { for } 7 \text { days, then } \\
4.8 \mathrm{~g} \mathrm{~d}^{-1} \text { for } 7 \text { days, then } \\
5.6 \mathrm{~g} \mathrm{~d}^{-1} \text { for } 7 \text { days, then } \\
6.4 \mathrm{~g} \mathrm{~d}^{-1} \text { for } 49 \text { days }\end{array}$ & 414.4 & $\begin{array}{l}\mathrm{BA}=1.046 \\
\quad(0.856-1.237) \\
\mathrm{Pla}=0.105 \\
(0.079-0.130)\end{array}$ \\
\hline Jordan et al. 2010 & $\begin{array}{l}\text { Recreational males } \\
8 \mathrm{BA} \\
9 \mathrm{Pla}\end{array}$ & $\begin{array}{l}\text { Incremental treadmill test to } \\
\text { exhaustion }\end{array}$ & $6 \mathrm{~g} \mathrm{~d}^{-1}$ for 28 days & 168 & $\begin{array}{c}\mathrm{BA}=0.185 \\
\quad(0.041-0.189) \\
\mathrm{Pla}=0.070 \\
\quad(0.053-0.098)\end{array}$ \\
\hline $\begin{array}{l}\text { Kendrick et al. } \\
2008\end{array}$ & $\begin{array}{l}\text { Male PE students } \\
13 \mathrm{BA} \\
13 \mathrm{Pla}\end{array}$ & $\begin{array}{l}\text { Whole body strength } \\
\text { Isokinetic force production } \\
\text { Muscular endurance }\end{array}$ & $6.4 \mathrm{~g} \mathrm{~d}^{-1}$ for 70 days & 448 & $\begin{array}{l}\mathrm{BA}=0.691 \\
\quad(0.613-1.033) \\
\mathrm{Pla}=0.654 \\
\quad(0.586-1.053)\end{array}$ \\
\hline $\begin{array}{l}\text { Kern and } \\
\text { Robinson } 2011\end{array}$ & $\begin{array}{l}\text { Male wrestlers and } \\
\text { footballers } \\
17 \mathrm{BA} \\
20 \mathrm{Pla}\end{array}$ & $\begin{array}{l}\text { Sprint running } \\
\text { Muscular endurance }\end{array}$ & $4 \mathrm{~g} \mathrm{~d}^{-1}$ for 60 days & 224 & $\begin{array}{l}\mathrm{BA}=0.255 \\
\quad(0.163-0.374) \\
\mathrm{Pla}=0.176 \\
\quad(0.089-0.297)\end{array}$ \\
\hline Sale et al. 2011 & $\begin{array}{l}\text { Recreational males } \\
10 \mathrm{BA} \\
10 \mathrm{Pla}\end{array}$ & $\begin{array}{l}\text { Cycle capacity at } 110 \% \\
\text { power }_{\max }\end{array}$ & $6.4 \mathrm{~g} \mathrm{~d}^{-1}$ for 28 days & 179 & $\begin{array}{l}\mathrm{BA}=0.964 \\
\quad(0.855-1.072) \\
\mathrm{Pla}=0.104 \\
(0.095-0.113)\end{array}$ \\
\hline $\begin{array}{l}\text { Smith et al. 2009a } \\
(3 \mathrm{w})\end{array}$ & $\begin{array}{l}\text { Recreational males } \\
18 \mathrm{BA} \\
18 \mathrm{Pla}\end{array}$ & Cycle capacity at $110 \% \mathrm{VO}_{2} \max$ & $6 \mathrm{~g} \mathrm{~d}^{-1}$ for 21 days & 126 & $\begin{array}{l}\mathrm{BA}=0.600 \\
\quad(0.395-0.979) \\
\mathrm{Pla}=0.607 \\
\quad(0.425-1.036)\end{array}$ \\
\hline $\begin{array}{l}\text { Smith et al. 2009a } \\
(6 \mathrm{w})\end{array}$ & $\begin{array}{l}\text { Recreational males } \\
18 \mathrm{BA} \\
18 \mathrm{Pla}\end{array}$ & Cycle capacity at $110 \% V \mathrm{O}_{2} \max$ & $\begin{array}{l}6 \mathrm{~g} \mathrm{~d}^{-1} \text { for } 21 \text { days, then } \\
3 \mathrm{~g} \mathrm{~d}^{-1} \text { for } 21 \text { days }\end{array}$ & 189 & $\begin{array}{l}\mathrm{BA}=1.067 \\
\quad(0.807-1.864) \\
\mathrm{Pla}=1.180 \\
(0.889-1.837)\end{array}$ \\
\hline Stout et al. 2006 & $\begin{array}{l}\text { Healthy males } \\
12 \mathrm{BA} \\
13 \mathrm{Pla}\end{array}$ & $\begin{array}{l}\text { Incremental cycle test to } \\
\text { exhaustion }\end{array}$ & $\begin{array}{l}6.4 \mathrm{~g} \mathrm{~d}^{-1} \text { for } 6 \text { days, then } \\
3.2 \mathrm{~g} \mathrm{~d}^{-1} \text { for } 22 \text { days }\end{array}$ & 108.8 & $\begin{array}{l}\mathrm{BA}=0.489 \\
\mathrm{Pla}=-0.063\end{array}$ \\
\hline Stout et al. 2007 & $\begin{array}{l}\text { Healthy females } \\
11 \mathrm{BA} \\
11 \mathrm{Pla}\end{array}$ & $\begin{array}{l}\text { Incremental cycle test to } \\
\text { exhaustion }\end{array}$ & $\begin{array}{l}3.2 \mathrm{~g} \mathrm{~d}^{-1} \text { for } 7 \text { days, then } \\
6.4 \mathrm{~g} \mathrm{~d}^{-1} \text { for } 21 \text { days }\end{array}$ & 156.8 & $\begin{array}{l}\mathrm{BA}=0.217 \\
\quad(0.051-0.421) \\
\mathrm{Pla}=-0.023 \\
\quad(-0.061 \text { to } 0.006)\end{array}$ \\
\hline Stout et al. 2008 & $\begin{array}{l}\text { Elderly males and } \\
\text { females } \\
12 \mathrm{BA} \\
14 \mathrm{Pla}\end{array}$ & $\begin{array}{l}2 \text { min cycling bouts at } \\
\text { ascending workloads }\end{array}$ & $2.4 \mathrm{~g} \mathrm{~d}^{-1}$ for 90 days & 216 & $\begin{array}{l}\mathrm{BA}=2.648 \\
\mathrm{Pla}=-0.007\end{array}$ \\
\hline
\end{tabular}


Table 1 continued

\begin{tabular}{|c|c|c|c|c|c|}
\hline Reference & Participants & Exercise protocol & Supplementation protocol & $\begin{array}{l}\text { Total } \\
\text { dosage }(g)\end{array}$ & $\begin{array}{l}\text { Effect sizeof all } \\
\text { measures } \\
\text { Median (range) }\end{array}$ \\
\hline Sweeney et al. 2010 & $\begin{array}{l}\text { Recreational } \\
\text { males } \\
9 \mathrm{BA} \\
10 \mathrm{Pla}\end{array}$ & $\begin{array}{l}2 \text { bouts of } 5 \times 5 \mathrm{~s} \text { treadmill } \\
\text { sprints }\end{array}$ & $\begin{array}{l}4 \mathrm{~g} \mathrm{~d}^{-1} \text { for } 7 \text { days, then } \\
6 \mathrm{~g} \mathrm{~d}^{-1} \text { for } 28 \text { days }\end{array}$ & 196 & $\begin{array}{l}\mathrm{BA}=0.037 \\
\quad(0.003-0.072) \\
\mathrm{Pla}=0.116 \\
(0.065-0.191)\end{array}$ \\
\hline $\begin{array}{l}\text { Van Thienen et al. } \\
2009\end{array}$ & $\begin{array}{l}\text { Male cyclists } \\
9 \mathrm{BA} \\
8 \mathrm{Pla}\end{array}$ & $\begin{array}{l}\text { Incremental cycle test to } \\
\text { exhaustion } \\
\text { Simulate cycling road race }\end{array}$ & $\begin{array}{l}2 \mathrm{~g} \mathrm{~d}^{-1} \text { for } 14 \text { days, then } \\
3 \mathrm{~g} \mathrm{~d}^{-1} \text { for } 14 \text { days, then } \\
4 \mathrm{~g} \mathrm{~d}^{-1} \text { for } 28 \text { days }\end{array}$ & 182 & $\begin{array}{l}\mathrm{BA}=0.292 \\
\quad(0.149-0.449) \\
\mathrm{Pla}=0.060 \\
\quad(-0.113 \text { to } 0.417)\end{array}$ \\
\hline $\begin{array}{l}\text { Walter et al. } 2010 \\
(3 \mathrm{w})\end{array}$ & $\begin{array}{l}\text { Recreational } \\
\text { females } \\
14 \mathrm{BA} \\
19 \mathrm{Pla}\end{array}$ & $\begin{array}{l}\text { Incremental cycle test to } \\
\text { exhaustion }\end{array}$ & $6 \mathrm{~g} \mathrm{~d}^{-1}$ for 21 days & 126 & $\begin{array}{l}\mathrm{BA}=0.953 \\
\quad(0.873-1.034) \\
\mathrm{Pla}=0.537 \\
\quad(0.512-0.562)\end{array}$ \\
\hline $\begin{array}{l}\text { Walter et al. } 2010 \\
(6 \mathrm{w})\end{array}$ & $\begin{array}{l}\text { Recreational } \\
\text { females } \\
14 \mathrm{BA} \\
19 \mathrm{Pla}\end{array}$ & $\begin{array}{l}\text { Incremental cycle test to } \\
\text { exhaustion }\end{array}$ & $\begin{array}{l}6 \mathrm{~g} \mathrm{~d}^{-1} \text { for } 21 \text { days, then } \\
3 \mathrm{~g} \mathrm{~d}^{-1} \text { for } 21 \text { days }\end{array}$ & 189 & $\begin{array}{l}\mathrm{BA}=1.129 \\
\quad(1.080-1.178) \\
\mathrm{Pla}=0.791 \\
(0.780-0.802)\end{array}$ \\
\hline Zoeller et al. 2007 & $\begin{array}{l}\text { Healthy males } \\
12 \mathrm{BA} \\
13 \mathrm{Pla}\end{array}$ & $\begin{array}{l}\text { Incremental cycle test to } \\
\text { exhaustion }\end{array}$ & $\begin{array}{l}6.4 \mathrm{~g} \mathrm{~d}^{-1} \text { for } 6 \text { days, then } \\
3.2 \mathrm{~g} \mathrm{~d}^{-1} \text { for } 22 \text { days }\end{array}$ & 108.8 & $\begin{array}{l}\mathrm{BA}=0.117 \\
\quad(0.001-0.251) \\
\mathrm{Pla}=-0.152 \\
(-0.456 \text { to } 0.023)\end{array}$ \\
\hline
\end{tabular}

\section{Data analysis}

Pre- and post-supplementation mean and standard deviations (SD) were obtained from the original data included in the published papers. Where this information was not available (Sale et al. 2011; Derave et al. 2007; Kern and Robinson 2011) authors were contacted directly with a request for the required data. Unfortunately, further information was not received from Derave and his co-workers in relation to their data on isokinetic peak force production and, as such, this data is not included in the meta-analysis. Where standard error of the mean (SEM) rather than standard deviation was reported, this was calculated as $\mathrm{SD}=\mathrm{SEM} \times \sqrt{n}$, where $n$ is the group sample size. The effectiveness of the supplementation (for BA and Pla groups) was quantified by calculating the effect size, which is the difference between the pre- and post-supplementation measures, divided by the pooled SD of the two occasions. Therefore, effect size represents a common measure of treatment effectiveness, which allows the findings of individual studies to be analysed together. Where a smaller number represents a better result (such as running performance), the subtraction is reversed and thus a positive effect size still represents a positive treatment effect. Each effect size was then corrected to adjust for any positive bias due to small sample size (Thomas and French 1986). The studies of Hill et al. (2007), Smith et al. (2009a) and Walter et al. (2010) reported dose and exercise data pre-, mid- and post-supplementation, allowing each of these studies to be subdivided into two separate protocols, i.e., pre- to midsupplementation data and pre- to post-supplementation data.

\section{Classifying of variables}

Exercise measures were analysed as one complete group for the overall effect of $\beta$-alanine supplementation compared to a placebo. Due to the mechanisms by which $\beta$-alanine is proposed to have an ergogenic effect on exercise, the data were then sub-divided.

Where possible, data were separated into those generated by exercise capacity and exercise performance tests. Exercise capacity tests require the participant to exert themselves to the point of volitional exhaustion, rather than to a fixed end point as is the case in exercise performance tests, therefore capacity tests are usefully employed when a maximal production of $\mathrm{H}^{+}$is desired. Although exercise performance tests are deemed to have a greater level of ecological validity, they rely upon intrinsic pacing strategies which may not elicit optimal performance (Hinckson and Hopkins 2005). If there is no fixed pacing strategy, as may be the case in sub-elite athletes, then the effects of an intervention might be masked by large variance; if there is a fixed pacing strategy, as may be the case in elite or 
experienced athletes, it may not allow the effects of an intervention to be shown. Therefore, exercise capacity and exercise performance data were analysed separately.

Measures were also sub-divided by exercise duration, given that $\beta$-alanine supplementation increases carnosine concentrations in skeletal muscle and acts indirectly to increase muscle buffering capacity. During exercise of less than $60 \mathrm{~s}$ duration, $\mathrm{H}^{+}$accumulation is unlikely to be sufficient to be the primary cause of fatigue as Bogdanis et al. (1998) showed that a reduced muscle $\mathrm{pH}$, induced by sprint exercise prior to the test, did not affect performance of a single bout of $30 \mathrm{~s}$ maximal cycling. Maximum $\mathrm{H}^{+}$ accumulation occurs after approximately $4 \mathrm{~min}$ of highintensity exercise, as Osnes and Hermansen (1972) demonstrated with greatest blood lactate values and lowest blood $\mathrm{pH}$ values seen after running $1,500 \mathrm{~m}(3 \mathrm{~min} 48 \mathrm{~s})$ compared to distances ranging from 100 to $5,000 \mathrm{~m}$. Therefore, the tests included in this meta-analysis were subdivided into those lasting $<60 \mathrm{~s}, 60-240 \mathrm{~s}$ and $>240 \mathrm{~s}$.

Finally, the dose of $\beta$-alanine administered (above or below the average daily and total dose, as determined by mean and median) was also investigated to determine if there was a direct link between the dose and the effect of $\beta$-alanine. Information regarding which tests were included in each grouping is available in Table 2 .

\section{Statistical analysis}

With the data divided as BA and Pla groups, and the number of effect sizes in each group dictated by the variable being investigated, the data were analysed for skewness, kurtosis and normality of distribution. In all cases, the data were not normally distributed, and therefore independent samples Mann-Whitney $U$ tests and Spearman's correlation coefficients were employed using SPSS version 18. Data are presented as median (interquartile range) unless otherwise stated and statistical significance was accepted at $P \leq 0.05$.

\section{Results}

Studies

Fifteen published investigations met the inclusion criteria (see Table 1 for study details). Several studies employed multiple exercise tests and multiple measures within those tests, therefore 57 effect sizes were calculated for inclusion in the analysis. A total of 360 participants were included, subdividing into 174 participants in the BA group and 186 participants in the Pla group; the average group size was 12 participants, with a range of 7-20 participants. Of the 360 participants, $20.3 \%$ were female and $7.2 \%$ were elderly males and females (range 55-92 years), but the vast majority of participants (77.2\%) were young, healthy, active males. Of the 15 studies included in the meta-analysis, 8 acknowledge the donation of the supplement used from a commercial company and 3 state the brand of supplement used, but 4 studies make no reference as to the source of the $\beta$-alanine administered (Stout et al. 2006; Zoeller et al. 2007; Smith et al. 2009a; Walter et al. 2010). Furthermore, five manuscripts acknowledge an element of financial support for their study from a commercial company (Hill et al. 2007; Smith et al. 2009a; Zoeller et al. 2007; Stout et al. 2006; Jordan et al. 2010).

\section{Overall}

The effect size of the Pla group was 0.108 ( -0.019 to 0.487 ) and the effect size of the BA group was $0.374(0.140-0.747)$. This equated to a significant effect of $\beta$-alanine supplementation compared to a placebo $(P=0.002)$. Further data analysis indicates that supplementation with a total of $179 \mathrm{~g}$ of $\beta$-alanine (the median dose across all studies) would result in a median improvement of $2.85 \%$ compared with a placebo.

Exercise performance and capacity

Twelve exercise performance measures were employed in six studies (see Table 2 for details). When combined, tests such as rowing performance (Baguet et al. 2010a), running performance (Derave et al. 2007; Kern and Robinson 2011) and maximal strength tests (Kendrick et al. 2008) had an effect size of 0.150 ( -0.059 to 0.473$)$ in the Pla group and $0.326(0.164-0.549)$ in the BA group, although this was not significantly different $(P=0.204$; Fig. 1$)$.

However, there was a significant difference between BA and Pla groups when exercise capacity was assessed $(P=0.013)$. Thirteen of the fifteen studies included in this meta-analysis employed a total of 27 exercise capacity measures to investigate the effects of $\beta$-alanine supplementation. BA groups had an effect size of 0.591 (0.341-1.071) while the Pla groups had a smaller effect size of 0.156 (0.040-0.566; Fig. 1).

\section{Exercise durations}

The 57 exercise measures included in this meta-analysis were also divided into those lasting $<60 \mathrm{~s}, 60-240 \mathrm{~s}$ and $>240$ s (see Table 2 for details). For the 14 measures lasting $<60$ s there was no significant difference between the effect sizes in the BA and Pla groups [0.193 (0.072-0.540) and 0.118 ( -0.037 to 0.471$) ; P=0.312$ ]. For the 9 measures lasting $60-240 \mathrm{~s}$ there was a significant difference between 
Table 2 A summary of the studies and measures included in the sub-sections of the meta-analysis

\begin{tabular}{|c|c|c|c|c|}
\hline Reference & Test & Measure & $\mathrm{C} / \mathrm{P}$ & $1 / 2 / 3$ \\
\hline Baguet et al. 2010a & $2,000 \mathrm{~m}$ rowing & $2,000 \mathrm{~m}$ rowing time & $\mathrm{P}$ & 3 \\
\hline \multirow[t]{2}{*}{ Derave et al. 2007} & Sprint running & $400 \mathrm{~m}$ running time & $\mathrm{P}$ & 1 \\
\hline & Isometric endurance@ 45\% MVC & Isometric contraction time to exhaustion & $\mathrm{C}$ & 2 \\
\hline \multirow[t]{2}{*}{ Hill et al. 2007 (4w) } & \multirow[t]{2}{*}{ Cycle capacity at $110 \%$ power $_{\max }$} & Total work done & $\mathrm{C}$ & 2 \\
\hline & & Cycle time to exhaustion & $\mathrm{C}$ & 2 \\
\hline \multirow[t]{2}{*}{ Hill et al. 2007 (10w) } & \multirow[t]{2}{*}{ Cycle capacity at $110 \%$ power $_{\max }$} & Total work done & $\mathrm{C}$ & 2 \\
\hline & & Cycle time to exhaustion & $\mathrm{C}$ & 2 \\
\hline \multirow[t]{5}{*}{ Jordan et al. 2010} & \multirow[t]{5}{*}{ Incremental treadmill test to exhaustion } & $V \mathrm{O}_{2} \max$ & $\mathrm{C}$ & 3 \\
\hline & & $V \mathrm{O}_{2}$ at $\mathrm{OBLA}$ & & 3 \\
\hline & & $\% \mathrm{VO}_{2} \max$ at OBLA & & 3 \\
\hline & & Heart rate at OBLA & & 3 \\
\hline & & $\%$ Heart rate max at OBLA & & 3 \\
\hline \multirow[t]{3}{*}{ Kendrick et al. 2008} & Whole body strength & Cumulative box squat, bench press and dead lift & $\mathrm{P}$ & 1 \\
\hline & Isokinetic force production & Isokinetic force production & $\mathrm{P}$ & 1 \\
\hline & Muscular endurance & Upper arm curl repetitions to exhaustion & $\mathrm{C}$ & 1 \\
\hline \multirow[t]{4}{*}{ Kern and Robinson 2011} & Sprint running & Wrestlers 300 yd shuttle run time & $\mathrm{P}$ & 2 \\
\hline & Muscular endurance & Footballers 300 yd shuttle run time & $\mathrm{P}$ & 1 \\
\hline & & Wrestlers $90^{\circ}$ flexed-arm hang & $\mathrm{C}$ & 2 \\
\hline & & Footballers $90^{\circ}$ flexed-arm hang & $\mathrm{C}$ & 1 \\
\hline \multirow[t]{2}{*}{ Sale et al. 2011} & Cycle capacity at $110 \%$ Power $_{\max }$ & Total work done & $\mathrm{C}$ & 2 \\
\hline & & Cycle time to exhaustion & $\mathrm{C}$ & 2 \\
\hline \multirow[t]{4}{*}{ Smith et al. 2009a (3w) } & Cycle capacity at $110 \% \mathrm{VO}_{2}$ peak & Total work done & $\mathrm{C}$ & 3 \\
\hline & & Cycle time to exhaustion & $\mathrm{C}$ & 3 \\
\hline & & $V \mathrm{O}_{2}$ peak & $\mathrm{C}$ & 3 \\
\hline & & Ventilatory threshold & & 3 \\
\hline \multirow[t]{4}{*}{ Smith et al. 2009a (6w) } & Cycle capacity at $110 \% \mathrm{VO}_{2}$ peak & Total work done & $\mathrm{C}$ & 3 \\
\hline & & Cycle time to exhaustion & $\mathrm{C}$ & 3 \\
\hline & & $V \mathrm{O}_{2}$ peak & $\mathrm{C}$ & 3 \\
\hline & & Ventilatory threshold & & 3 \\
\hline Stout et al. 2006 & Incremental cycle test to exhaustion & Physical work capacity at fatigue threshold & $\mathrm{C}$ & 3 \\
\hline \multirow[t]{4}{*}{ Stout et al. 2007} & Incremental cycle test to exhaustion & Physical work capacity at fatigue threshold & $\mathrm{C}$ & 3 \\
\hline & & Cycle time to exhaustion & $\mathrm{C}$ & 3 \\
\hline & & $V \mathrm{O}_{2}$ peak & $\mathrm{C}$ & 3 \\
\hline & & Ventilatory threshold & & 3 \\
\hline Stout et al. 2008 & 2 min cycling bouts at ascending workloads & Physical work capacity at fatigue threshold & $\mathrm{C}$ & 3 \\
\hline \multirow[t]{4}{*}{ Sweeney et al. 2010} & 2 bouts of $5 \times 5 \mathrm{~s}$ treadmill sprints & Horizontal power (mean)\% & $\mathrm{P}$ & 1 \\
\hline & & Horizontal power (peak)\% & $\mathrm{P}$ & 1 \\
\hline & & Performance decrease (mean) & & 1 \\
\hline & & Performance decrease (peak) & & 1 \\
\hline \multirow[t]{6}{*}{ van Thienen et al. 2009} & Incremental cycle test to exhaustion & Time to exhaustion & $\mathrm{C}$ & 3 \\
\hline & Simulated cycling road race & Mean power output in 10 min time trial & $\mathrm{P}$ & 3 \\
\hline & & Peak power output in $30 \mathrm{~s}$ sprint & $\mathrm{P}$ & 1 \\
\hline & & Mean power output in $30 \mathrm{~s}$ sprint & $\mathrm{P}$ & 1 \\
\hline & & Final power output in $30 \mathrm{~s}$ sprint & $\mathrm{P}$ & 1 \\
\hline & & $\%$ Fatigue in $30 \mathrm{~s}$ sprint & & 1 \\
\hline \multirow[t]{2}{*}{ Walter et al. $2010(3 \mathrm{w})$} & Incremental cycle test to exhaustion & $\mathrm{VO}_{2}$ peak & $\mathrm{C}$ & 3 \\
\hline & & Power output at ventilatory threshold & & 3 \\
\hline
\end{tabular}


Table 2 continued

\begin{tabular}{|c|c|c|c|c|}
\hline Reference & Test & Measure & $\mathrm{C} / \mathrm{P}$ & $1 / 2 / 3$ \\
\hline \multirow[t]{2}{*}{ Walter et al. $2010(6 \mathrm{w})$} & \multirow[t]{2}{*}{ Incremental cycle test to exhaustion } & $V \mathrm{O}_{2}$ peak & $\mathrm{C}$ & 3 \\
\hline & & Power output at ventilatory threshold & & 3 \\
\hline \multirow[t]{8}{*}{ Zoeller et al. 2007} & \multirow[t]{8}{*}{ Incremental cycle test to exhaustion } & Time to exhaustion & $\mathrm{C}$ & 3 \\
\hline & & $V \mathrm{O}_{2}$ peak & $\mathrm{C}$ & 3 \\
\hline & & $V \mathrm{O}_{2}$ at ventilatory threshold & & 3 \\
\hline & & $\% \mathrm{VO}_{2}$ peak at ventilatory threshold & & 3 \\
\hline & & Power output at ventilatory threshold & & 3 \\
\hline & & $V \mathrm{O}_{2}$ at lactate threshold & & 3 \\
\hline & & $\% \mathrm{VO}_{2}$ peak at lactate threshold & & 3 \\
\hline & & Power output at lactate threshold & & 3 \\
\hline
\end{tabular}

$\mathrm{P}$ indicates that the measure was included in the exercise performance analysis, $\mathrm{C}$ indicates that the measure was included in the exercise capacity analysis, 1 indicates that the measure was included in the $<60 \mathrm{~s}$ exercise duration analysis, 2 indicates that the measure was included in the 60-240 s exercise duration analysis, 3 indicates that the measure was included in the $>240$ s exercise duration analysis

$O B L A$ onset of blood lactate accumulation, $M V C$ maximum voluntary contraction

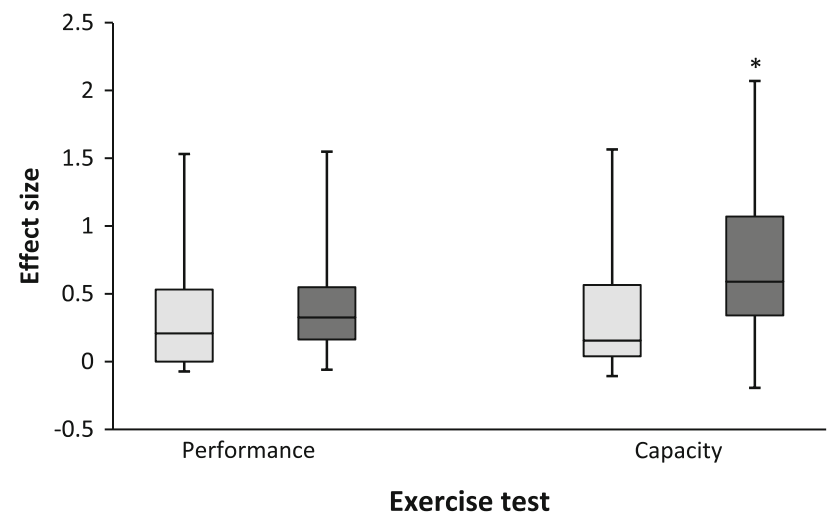

Fig. 1 The effect size of Pla and BA groups when subdivided by type of exercise test or measure. Light grey represents Pla groups and dark grey represents BA groups. * denotes significantly greater than Pla $(P=0.013)$

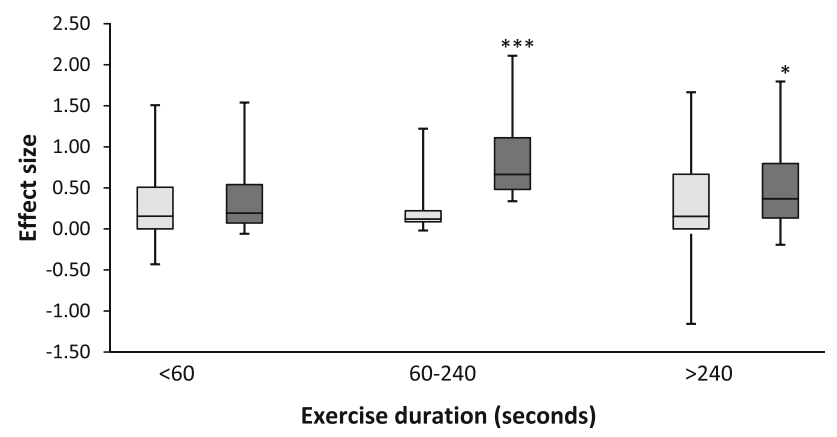

Fig. 2 The effect size of Pla and BA groups when subdivided by exercise duration. Light grey represents Pla groups and dark grey represents BA groups. * denotes significantly greater than Pla $(P=0.046), * * *$ denotes significantly greater than Pla $(P=0.001)$

the effect size of the BA and Pla groups [0.665 (0.481-1.110) and $0.121(0.087-0.221) ; P=0.001]$. However, once exercise duration increased over $240 \mathrm{~s}$ the beneficial effects of $\beta$-alanine supplementation from the 34 measures become less pronounced, although still significant [BA 0.368 (0.133-0.797), Pla 0.095 ( -0.059 to 0.607$) ; P=0.046]$. Figure 2 demonstrates this pattern.

\section{Dosage}

A large variety of supplementation protocols were employed, meaning that the total amount of $\beta$-alanine ingested by each participant varied from 108.8 (Stout et al. 2006; Zoeller et al. 2007) to $448 \mathrm{~g}$ (Kendrick et al. 2008), the daily dosage varied from 2.4 (Stout et al. 2008) to $6.4 \mathrm{~g} \mathrm{~d}^{-1}$ (Sale et al. 2011; Kendrick et al. 2008) and the individual maximum dosage administered varied from 800 to $2,000 \mathrm{mg}$, although Smith et al. (2009a) and Jordan et al. (2010) do not provide this information. The effect size of the dosage administered (total and $\mathrm{g} \mathrm{d}^{-1}$ ) was analysed as those above and below the median dose [total dose $179 \mathrm{~g}$ (126-196 g); daily dose $5.12 \mathrm{~g} \mathrm{~d}^{-1}$ (4.10-5.98 $\left.\mathrm{g} \mathrm{d}^{-1}\right)$ ] when all studies were taken together. There was no relationship between the dose of $\beta$-alanine administered and the difference between the effect size of the BA and Pla groups seen in the exercise measures $(P=0.337)$. The difference in the median effect size between the BA and Pla groups for each study is plotted in relation to the total dose of $\beta$-alanine supplemented in Fig. 3. Through regression analysis, the data of Stout et al. (2008; data point 13 in Fig. 3) were shown to have a standard residual value of 3.54, indicating that it may be an outlier. However, it's exclusion from the analysis did not result in a relationship between dose and effect size difference, and therefore this study remained in the metaanalysis. 
Fig. 3 The difference in the median effect size of the BA and Pla groups of each study in relation to the total dose of $\beta$-alanine supplemented

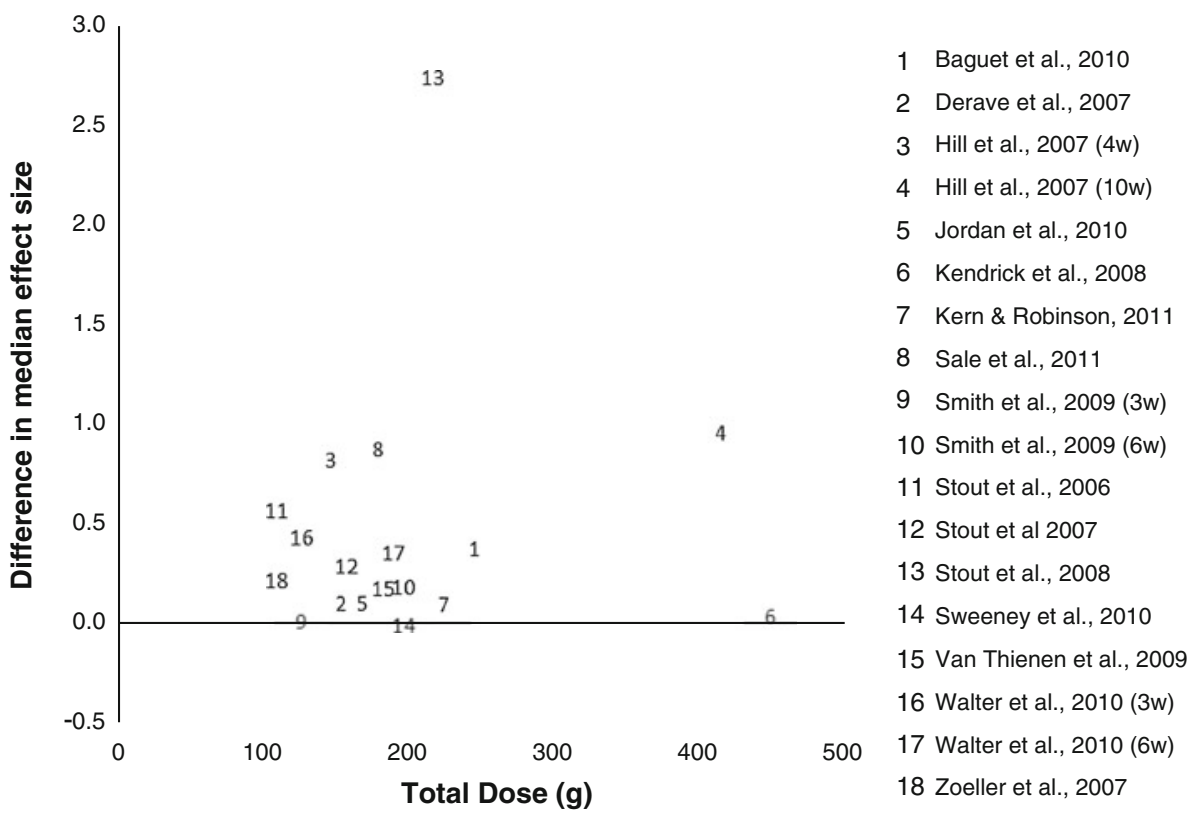

\section{Discussion}

To our knowledge, this is the first meta-analysis to be published on this topic and it shows that there is a significant effect of $\beta$-alanine supplementation on all exercise measures when taken as a single group. Analysis indicates that supplementation with a total of $179 \mathrm{~g}$ of $\beta$-alanine (the median dose across all studies) would result in a median improvement of $2.85 \%$ compared with a placebo. Assuming a linear relationship between running speed and percentage effect, if this improvement was extrapolated and applied to a sporting event lasting around $4 \mathrm{~min}$, such as a 1,500 m run, performance time would be improved by $\sim 6 \mathrm{~s}$. This improvement would be sufficient to move the last place finalist in the men's 1,500 m at the Beijing 2008 Olympic games to a bronze medal position. It should be noted that this calculation is based upon the median effect across several studies, and the vast majority of participants in the studies of this meta-analysis are recreationally active individuals rather than elite athletes. Furthermore, this meta-analysis has shown, from the data available to date, that $\beta$-alanine supplementation does not result in an improvement in performance-based measures, although the number of performance tests conducted on $\beta$-alanine supplementation is comparatively few $(n=12)$. Of these, only one (300 yard shuttle run; Kern and Robinson 2011) falls within the time frame in which $\beta$-alanine supplementation is most efficacious (60-240 s). Currently only one exercise test (the cycling capacity test at $110 \%$ power max) has been repeated with different subjects taking $\beta$-alanine (Hill et al. 2007; Sale et al. 2011). These studies have shown that, with 145.6 and $179 \mathrm{~g}$ of $\beta$-alanine, exercise capacity (time to exhaustion) was improved by 11.8 and $12.1 \%$ (Hill et al.
2007; Sale et al. 2011). Therefore, given the potential demonstrated for significant improvements in exercise lasting 60-240 s, this meta-analysis highlights the need for more studies investigating the effects of $\beta$-alanine supplementation on exercise performance of this duration.

\section{Performance/Capacity}

$\beta$-alanine supplementation improves exercise capacity $(P=0.013)$, with BA showing a 'moderate' effect size compared to Pla (Cohen 1988). However, to date, the available data suggests that $\beta$-alanine supplementation has no benefit on measures of exercise performance rather than exercise capacity. This result is perhaps unsurprising as only 2 of the 12 performance measures included in the meta-analysis have shown a significant difference between the BA and Pla groups (mean power output and peak power output in a $30 \mathrm{~s}$ cycle sprint, after $125 \mathrm{~min}$ of previous cycling; Van Thienen et al. 2009), although a third test reported a strong trend $(P=0.07)$ for an improvement in the supplemented group $(2,000 \mathrm{~m}$ rowing; Baguet et al. 2010a). Many of the tests and measures employed showed improvements in both groups, which could be due to a potential 'placebo effect', or possibly a greater participant understanding of how to perform the trial (Laursen et al. 2003). However, this is unlikely to be the true explanation for the results seen here as 3 of the 6 studies conducted full familiarisation trials with the participants prior to testing (Kendrick et al. 2008; Sweeney et al. 2010; van Thienen et al. 2009), and the other three studies employed tests with which the participants were already fully familiar (Derave et al. 2007; Baguet et al. 2010a; Kern and Robinson 2011). 
Although it can be argued that performance tests are more ecologically valid (Coyle et al. 1991), they require pacing strategies to be employed, which may be a confounding factor (Hinckson and Hopkins 2005). Exercise capacity tests do not require this skill and are often of more use in exercise physiology research, where mechanistic investigations are often the focus rather than the artificial recreation of a sporting setting. Furthermore, exercise capacity tests are, by their very nature, maximal and will, therefore maximally stress the homeostasis of the internal environment. Exercise performance tests may not be maximal due to the use of pacing strategies, be these consistent strategies which mask the effect of an intervention, or inconsistent strategies which increase variability. It is possible that differences in the efficacy of $\beta$-alanine supplementation between performance and capacity tests and measures exist due to these factors.

\section{Exercise intensity and duration}

Currently it would seem likely that the main ergogenic mechanism by which $\beta$-alanine acts is through an elevation in carnosine synthesis within the muscle (Harris et al. 2006), which in turn buffers the $\mathrm{H}^{+}$accumulation that occurs during high-intensity exercise (Hill et al. 2007). There are other proposed mechanisms by which $\beta$-alanine supplementation can influence exercise performance, namely through acting as a sacrificial peptide to protect against glycation, acting as an anti-oxidant and/or increasing calcium sensitivity in contractile fibres. Readers are directed to the review articles of Sale et al. (2010) and Derave et al. (2010) for more detailed discussion of these possibilities. The data in this meta-analysis clearly shows that exercise of a duration less than $60 \mathrm{~s}$ is not improved by $\beta$-alanine supplementation, while exercise of 60-240 s clearly is improved, and exercise over $240 \mathrm{~s}$ is also improved, although to a lesser extent.

The data presented here provide further evidence of the ergogenic effects of $\beta$-alanine supplementation to augment the intramuscular buffering of $\mathrm{H}^{+}$, which accumulate during high-intensity exercise lasting 1-4 min, a period when anaerobic energy sources can contribute between 20 and $60 \%$ of the total energy requirement (Maughan et al. 1997). The cause of fatigue in exercise of less than $60 \mathrm{~s}$ is unlikely to be an extreme acidosis and more likely to be due to the gradual decline in anaerobic ATP production and/or an increase in ADP accumulation, and therefore the increased ability of the muscle to buffer $\mathrm{H}^{+}$is unlikely to be fully utilised. However, it should be noted that, despite previous research suggesting that a reduced muscle $\mathrm{pH}$ did not affect performance of a single bout of $30 \mathrm{~s}$ maximal cycling (Bogdanis et al. 1998), Suzuki et al. (2002) showed a positive correlation between muscle carnosine concentration and power output towards the end of a $30 \mathrm{~s}$ maximal cycling bout. Therefore, it is likely that the relationship shown by Suzuki et al. (2002) between carnosine concentrations and exercise performance followed from the significant correlation also observed between carnosine and muscle fibre type. It is possible that, the area occupied by type II muscle fibres was more important to $30 \mathrm{~s}$ maximal sprint cycling than $\mathrm{pH}$ regulation directly. This metaanalysis supports the findings of Bogdanis et al. (1998) that muscle buffer capacity does not affect performance during very short duration $(<60 \mathrm{~s})$ exercise.

Of interest are the data generated relating to exercise lasting over $240 \mathrm{~s}$ as here, $\mathrm{H}^{+}$accumulation and muscle lactate concentrations are still likely to be high, but the increasing involvement of aerobic metabolism will not increase the acidosis in the muscle further. Therefore, other pathways related to $\beta$-alanine supplementation and the role of carnosine in the muscle, such as an effect of $\beta$-alanine on delaying the fatigue induced increase in ventilation rate (Stout et al. 2007), may be the mechanism behind this ergogenic effect. Unfortunately, many of the papers employing exercise lasting $>240 \mathrm{~s}$ did not report the exact exercise duration. Therefore, it was not possible to normalise these data for their duration, which would have allowed us to examine if a relationship existed between $\beta$-alanine supplementation and exercise duration $>240 \mathrm{~s}$. As such, the effects of $\beta$-alanine on exercise $>240 \mathrm{~s}$ warrants further research.

\section{$\beta$-alanine dosage}

Stellingwerff (in press) recently published findings which demonstrate that as the dose of $\beta$-alanine supplemented increases, the duration of supplementation required to elicit changes in the muscle carnosine content is reduced. There is currently no known threshold to the storage of carnosine in muscle and therefore it would seem logical that the more $\beta$-alanine that is supplemented, be that at a lower dose over a longer duration or at a higher dose over a shorter duration, the more carnosine can be synthesised and stored in the muscle. This could lead to a greater muscle buffering capacity during high-intensity exercise and therefore an improvement in exercise outcomes. Indeed, this theory is partially supported by the data of Hill et al. (2007) in which total work done during a cycling capacity test increased by $13 \%$ after 4 weeks and a further $3.2 \%$ after 10 weeks of $\beta$-alanine supplementation, with no changes shown in the control group. Hill et al. (2007) demonstrated a continuing improvement in exercise outcome with increased amounts of $\beta$-alanine ingested, although the relationship was not linear.

However, what this meta-analysis suggests is that the dose of $\beta$-alanine supplemented, and therefore presumably 
the magnitude of the change in muscle carnosine content, does not influence the outcome of exercise measures. When the difference in the effect size of the BA and Pla groups for each measure is compared across studies, there does not appear to be a relationship between the dose of $\beta$-alanine supplemented and median effect size of all the measures at that dose. Sweeney et al. (2010) had the smallest median effect size difference $[-0.027(-0.136$ to 0.007$)]$ but one of the larger total doses of $\beta$-alanine supplemented (196 g). Similarly, Kendrick et al. (2008) used the greatest dose of $\beta$-alanine, but had one of the smaller median effect size differences $[0.018(-0.029$ to 0.027$)]$. The data of Stout et al. (2008) had a standard residual value of 3.54, indicating that it may be an outlier. However, this data was not removed from the analysis as presently the shape of the dose-response curve for $\beta$-alanine supplementation is unknown. Unfortunately, due to many different tests and measures performed in the $\beta$-alanine supplementation studies to date, which do not always focus on $\mathrm{H}^{+}$accumulation (as discussed above), and the use of different dosing strategies, it remains unclear whether there is a direct link between the dose of $\beta$-alanine supplemented and the exercise outcome. Indeed, where large doses of $\beta$-alanine were supplemented, but only small differences in effect size were shown between BA and Pla groups, this could be due to the exercise test or measure employed, rather than the supplementation dose. This is a potential avenue for future research.

\section{Potential confounding factors of $\beta$-alanine research studies}

Research has shown that, in commercially available supplementation products, there is a substantial chance of contamination with banned substances and/or different concentrations of ingredients to those listed on the supplement container (Geyer et al. 2004). It is also possible that supplements contain other substances which may interfere with the uptake of the target compound, as in vitro tests have shown with taurine and $\beta$-alanine (Jessen 1994). Several studies included in this meta-analysis have used commercially available supplements, the purity of which does not appear to have been tested and/or reported. As such, future investigations should make every attempt to ensure the purity of the supplement used through independent analysis of the product. Where such efforts have been made, this should be included in the manuscript [see Sale et al. (2011) and Stout et al. (2006) for examples of good practice], allowing the reader to have full confidence in the data reported.

$\beta$-alanine causes paraesthesia in some individuals (Harris et al. 2006), a side effect which ethically should be included in participant information sheets issued to prior to participation in all studies. It would therefore be clear to any participant suffering from paraesthesia that they were on the active treatment rather than the placebo, effectively removing the blinding of the study. Therefore, particularly with exercise based investigations, the results may no longer be valid. Theoretically, any individual reporting paraesthesia should be excluded from the study and replacement participants should be recruited, although this rarely seems to occur or at least is rarely reported. As such, this is something that should be considered in future $\beta$-alanine studies. Indeed, the advent of new 'slow-release' formulations of $\beta$-alanine are working to address this potentially confounding factor (Harris et al. 2008), and Sale et al. (2011) have recently used this formulation and report no symptoms of paraesthesia in their participants. Subsequently, Decombaz et al. (2011) showed that ingesting $1.6 \mathrm{~g}$ of BA in the form of slow-release tablets resulted in no more sensory side effects than a placebo supplement and significantly less than when the same dose of BA was administered in pure solution.

The washout period for $\beta$-alanine has been shown to be 15 weeks or longer (Baguet et al. 2009; Stellingwerff (in press)). Studies must therefore ensure that all participants have been free from supplementation for a minimum of almost 4 months before participating in a $\beta$-alanine research study. Furthermore, this extensive washout period means that cross-over design studies in the field of $\beta$-alanine supplementation are unlikely to be possible, since a participants' fitness levels and dietary patterns might be expected to change over this duration.

Training programmes incorporated into some studies (Smith et al. 2009a; Walter et al. 2010; Kendrick et al. 2008) may be a confounding factor or might mask the effects of $\beta$-alanine. Although intracellular $\mathrm{pH}$ buffering has received much of the attention, several other mechanisms for the ergogenic effect of $\beta$-alanine supplementation have been proposed. These include the increase in $\mathrm{Ca}^{2+}$ sensitivity of the contractile fibres caused by elevated carnosine concentrations allowing the maintenance force production in the later stages of fatigue when $\mathrm{Ca}^{2+}$ release normally declines (Dutka and Lamb 2004), or the potential antioxidant effects of carnosine delaying the onset of fatigue during intense and prolonged exercise through the inhibition of $\mathrm{Ca}^{2+}$ sensitivity (Reid 2008). Therefore, while the area of $\beta$-alanine research is in its relative infancy, it might be more prudent to focus research efforts into confirming the mechanism or mechanisms by which $\beta$-alanine supplementation has an ergogenic effect.

Within sports science research, exercise tests are one of the most commonly used tools (Hinckson and Hopkins 2005), and a large variety of exercise tests and measures have been used to assess the efficacy of $\beta$-alanine supplementation. It has been suggested that exercise capacity tests have poor reliability when compared to performance 
tests $(26.6 \% \mathrm{CV}$ compared to $3.4 \% \mathrm{CV}$, Jeukendrup et al. 1996), although several authors have shown that, when participants have been well familiarised and tests are rigorously standardised and executed, exercise capacity tests can also have good levels of reliability (e.g., $4.4 \%$, Sale et al. 2011; 3\%, Watson et al. 2004). Unfortunately, the reliability of tests and measures employed are rarely reported, meaning that the significance of any alteration in exercise capacity or performance with $\beta$-alanine supplementation cannot be accurately interpreted. Authors should report the reliability of their exercise tests and measures in the manuscript to allow the reader to interpret the results in view of the sensitivity of the test or measure employed.

Another confounding factor applicable to all sports science research is the potential for studies to be underpowered, possibly through a lack/manipulation of the sample size estimation (Batterham and Atkinson 2005). This may be the case in some investigations presented here due to the large variance in participant numbers $(n=7$, Derave et al. 2007; $n=20$, Kern and Robinson 2011). Unfortunately however, retrospective power analysis calculated using effect size and variance is of limited use (Thomas 1997). Meta-analysis aims to partially address the imbalance of influence that studies with small sample sizes have (Hedges 1981) by correcting the effect size prior to averaging through the application of a correction factor leading to a virtually unbiased estimate of effect size (Thomas and French 1986).

Finally, care should be taken when generalising these findings to special populations, such as female athletes or elderly individuals. Only 3 of the 15 studies included female participants, and all of these studies employed exercise tests or measures lasting $>240 \mathrm{~s}$, where the effects of $\beta$-alanine supplementation were less pronounced than in the 60-240 s exercise duration group. Further, only 1 of the 15 studies included elderly participants, and this study also used an exercise testing protocol of $>240 \mathrm{~s}$.

\section{Limitations of meta-analysis as a research technique}

During a meta-analysis, studies with critical flaws in the methodology can be omitted from the analysis at the outset. However, meta-analysis does not allow the methodological quality of the studies included in the analysis to be taken into account in the reporting and interpretation of the results. Moja et al. (2005) suggests that, while even such gold standard review bodies as The Cochrane Reviews may fare well in the assessment of methodological quality of primary studies, they largely fail to take this into account in the interpretation of the results. It would seem that the establishment of a technique to allow the assessment of the methodological quality of individual studies, and therefore potentially weight their findings accordingly, is still underdeveloped, meaning there is still substantial room for future improvement in the meta-analytical technique.

As a widely acknowledged rule of thumb, it is easier to get positive findings published in peer reviewed journals than findings of a negative or no effect (Kirkwood and Sterne 2003). Therefore, when conducting any review, particularly a meta-analysis, there is a risk of bias in the findings towards a positive effect of an intervention. However, studies into $\beta$-alanine supplementation that have not shown a positive effect have been published (Zoeller et al. 2007; Walter et al. 2010; Kern and Robinson 2011; Sweeney et al. 2010; Kendrick et al. 2008; Baguet et al. 2010a), suggesting that this research field may not yet be tainted by publication bias to the same extent as others, although the extent of publication bias in a research field is difficult to estimate.

\section{Conclusion and recommendations}

The median overall effect of $\beta$-alanine supplementation is a $2.85 \%$ ( -0.37 to $10.49 \%)$ improvement in the outcome of an exercise measure, when $179 \mathrm{~g}$ of $\beta$-alanine is supplemented; although this value is likely to change dependent upon a variety of factors. In the only test to be repeated following 4 weeks of $\beta$-alanine supplementation across two different studies, increases in exercise capacity were indeed outside this range at $11.8 \%$ (Hill et al. 2007) and $12.1 \%$ (Sale et al. 2011). From the data available to date, it can be concluded that $\beta$-alanine supplementation elicits a significant ergogenic effect on high-intensity exercise, particularly in exercise capacity tests and measures, and where the exercise lasts between 1 and $4 \mathrm{~min}$. Areas which warrant further investigation due to the borderline efficacy of $\beta$-alanine, i.e., exercise lasting over $240 \mathrm{~s}$, have also been highlighted. This meta-analysis has shown that exercise performance tests and measures, and exercise of less than $60 \mathrm{~s}$ duration are not improved by $\beta$-alanine supplementation. Given the types, intensities and durations of exercise positively influenced by $\beta$-alanine supplementation, we maintain that the most likely mechanism supporting a benefit is through an increase in intracellular $\mathrm{pH}$ buffering as the result of increased muscle carnosine levels.

The diversity of the methodologies used in the assessment of the efficacy of $\beta$-alanine highlights the importance of clear logical progression through the different aspects of supplementation to eventually be able to produce a clear concise set of criteria for its efficacy. Authors should also make every attempt to demonstrate: the purity of the supplement used; the double blinding of the treatments; and the reliability of the exercise tests or measure employed. It would also be of interest to investigate if a link exists between dose of $\beta$-alanine administered, the degree of 
elevation in muscle carnosine content and the magnitude of the improvement in an exercise outcome. However, this area of research is still in its infancy and therefore any well conducted, double-blinded, randomised control trials with a good rationale should continue to be conducted.

Conflict of interest The authors have no conflict of interest to declare.

Open Access This article is distributed under the terms of the Creative Commons Attribution Noncommercial License which permits any noncommercial use, distribution, and reproduction in any medium, provided the original author(s) and source are credited.

\section{References}

Artioli GG, Gualano B, Smith A, Stout J, Lancha AH (2010) Role of $\beta$-alanine supplementation on muscle carnosine and exercise performance. Med Sci Sports Exerc 42:1162-1173

Baguet A, Reyngoudt H, Pottier A, Everaert I, Callens S, Achten E, Derave W (2009) Carnosine loading and washout in human skeletal muscles. J Appl Physiol 106:837-842

Baguet A, Bourgois J, Vanhee L, Achten E, Derave W (2010a) Important role of muscle carnosine in rowing performance. J Appl Physiol 109:1096-1101

Baguet A, Koppo K, Pottier A, Derave W (2010b) $\beta$-alanine supplementation reduces acidosis but not oxygen uptake responses during high-intensity cycling exercise. Eur J Appl Physiol 108:495-503

Bate-Smith EC (1938) The buffering of muscle in rigor: protein, phosphate and carnosine. J Physiol 92:336-343

Batterham AM, Atkinson G (2005) How big does my sample size need to be? A primer on the murky world of sample size estimation. Phys Ther Sport 6:153-163

Bogdanis GC, Nevill ME, Lakomy HKA, Boobis LH (1998) Power output and muscle metabolism during and following recovery from 10 and $20 \mathrm{~s}$ of maximal sprint exercise in humans. Acta Physiol Scand 163:261-272

Cohen J (1988) Statistical power analysis for the behavioural sciences, 2nd edn edn. Lawrence Erlbaum, Hillsdale

Coyle EF, Feltner ME, Kautz SA, Hamilton MT, Montain SJ, Baylor AM, Abraham LD, Petrek GW (1991) Physiological and biochemical factors associated with elite endurance cycling performance. Med Sci Sports Exerc 23:93-107

Dang VH, Kendrick IP, Kim CK, Harris RC, Kim HJ, Lam TQ, Bui TT, Wise JA (2006) The effect of $\beta$-alanine (carnosyn ${ }^{\text {TM }}$ ) supplementation on muscle carnosine synthesis during a 10 week program of strength training. Intern Conf Biochem Ex, Seoul

Decombaz J, Beaumont M, Vuichoud J, Bouisset F, Stellingwerff T (2011) Effect of slow-release $\beta$-alanine tablets on absorption kinetics and paresthesia. Amino Acids. doi:10.1007/s00726011-1169-7

Derave W, Ozdemir MS, Harris RC, Pottier A, Reyngoudt H, Koppo K, Wise JA, Achten E (2007) B-alanine supplementation augments muscle carnosine content and attenuates fatigue during repeated isokinetic contraction bouts in trained sprinters. J Appl Physiol 103:1736-1743

Derave W, Everaert I, Beeckman S, Baguet A (2010) Muscle carnosine metabolism and $\beta$-alanine supplementation in relation to exercise and training. Sports Med 40:247-263
Donaldson SKB, Hermansen L (1978) Differential direct effects of $\mathrm{H}^{+}$and $\mathrm{Ca}^{2+}$-activated force of skinned fibres from the soleus, cardiac, adductor magnus muscle of rabbits. Pflugers Arch 376: $55-65$

Dutka TL, Lamb GD (2004) Effect of carnosine on excitationcontraction coupling in mechanically skinned rat skeletal muscle. J Muscle Res Cell Motil 25:203-213

Fabiato A, Fabiato F (1978) Effects of pH on the myofilaments and the sarcoplasmic reticulum of skinned cells from cardiac and skeletal muscles. J Physiol 276:233-235

Geyer H, Parr MK, Mareck U, Reinhart U, Schrader Y, Schanzer W (2004) Analysis of non-hormonal nutritional supplements for anabolic-androgenic steroids-results of an international study. Int J Sports Med 25:124-129

Harris RC, Edwards RHT, Hultman E, Nordesjo LO, Nylind B (1976) The time course of phosphorylcreatine resynthesis during recovery of the quadriceps muscle in man. Pflugers Arch 367: $137-142$

Harris RC, Marlin DJ, Dunnett M, Snow DH, Hultman E (1990) Muscle buffering capacity and dipeptide content in the throughbred horse, greyhound dog and man. Comp Biochem Physiol 97:249-251

Harris RC, Dunnett M, Greenhaff PL (1998) Carnosine and taurine contents in individual fibres of human vastus lateralis muscle. J Sports Sci 16:639-643

Harris RC, Tallon MJ, Dunnett M, Boobis LH, Coakley J, Kim HJ, Fallowfield JL, Hill CA, Sale C, Wise JA (2006) The absorption of orally supplied beta-alanine and its effect on muscle carnosine synthesis in human vastus lateralis. Amino Acids 30:279-289

Harris RC, Jones G, Wise JA (2008) The plasma concentration-time profile of beta-alanine using a controlled release formulation (Carnosyn $^{\circledR}$ ). FASEB J 22, 701.9

Hedges LV (1981) Distribution theory for Glass's estimator of effect size and related estimators. J Educ Stat 6:107-128

Hill CA (2007). $\beta$-alanine supplementation and high intensity exercise. Unpublished PhD Thesis, University of Southampton

Hill CA, Harris RC, Kim HJ, Harris BD, Sale C, Boobis LH, Kim CK, Wise JA (2007) Influence of $\beta$-alanine supplementation on skeletal muscle carnosine concentrations and high intensity cycling capacity. Amino Acids 32:225-233

Hinckson EA, Hopkins WG (2005) Reliability of time to exhaustion analysed with critical-power and log-log modelling. Med Sci Sports Exerc 37:696-701

Hoffman J, Ratamess N, Kang J, Mangine G, Faigenbaum A, Stout J (2006) Effect of creatine and $\beta$-alanine supplementation on performance and endocrine responses in strength/power athletes. Int J Sport Nutr Exerc Metabol 16:430-446

Hoffman JR, Ratamess NA, Faigenbaum AD, Ross R, Kang J, Stout JR, Wise JA (2008a) Short-duration $\beta$-alanine supplementation increases training volume and reduces subjective feelings of fatigue in college football players. Nut Res 28:31-35

Hoffman JR, Ratamess NA, Ross R, Kang J, Magrelli J, Neese K, Faigenbaum AD, Wise JA (2008b) $\beta$-alanine and the hormonal response to exercise. Int J Sports Med 29:952-958

Jessen H (1994) Taurine and beta-alanine transport in an established human kidney cell line derived from the proximal tubule. Biochim Biophys Acta 1194:44-52

Jeukendrup A, Saris WHM, Brouns F, Kester ADM (1996) A new validated endurance performance test. Med Sci Sports Exerc 28:266-270

Jordan T, Lukaszuk J, Misic M, Umoren J (2010) Effect of betaalanine supplementation in the onset of blood lactate accumulation (OBLA) during treadmill running: Pre/post 3 treatment experimental design. J Int Soc Sports Nutr 7:20

Kendrick IP, Harris RC, Kim HJ, Kim CK, Dang VH, Lam TQ, Bui TT, Smith M, Wise JA (2008) The effects of 10 weeks of 
resistance training combined with $\beta$-alanine supplementation on whole body strength, force production, muscular endurance and body composition. Amino Acids 34:547-554

Kern BD, Robinson TL (2011) Effects of $\beta$-alanine supplementation on performance and body composition in collegiate wrestlers and football players. J Strength Cond Res 25:1804-1815

Kirkwood BR, Sterne JAC (2003) Systematic reviews and metaanalysis. In: essential medical statistics. Blackwell Science Ltd, Oxford

Laursen PB, Shing CM, Jenkins DG (2003) Reproducibility of a laboratory based $40 \mathrm{~km}$ cycle time-trial on a stationary wind trainer in highly trained cyclists. Int J Sports Med 24:481-485

Maughan RJ, Gleeson M, Greenhaff PL (1997) Biochemistry of exercise training. Oxford University Press, Oxford

Moja LP, Telaro E, D’Amico R, Moschetti I, Coe L, Liberati A (2005) Assessment of methodological quality of primary studies by systematic reviews: results of the metaquality cross sectional study. Br Med J 330:1053-1055

Ng RH, Marshall FD (1978) Regional and subcellular distribution of homocarnosine-carnosine synthetase in the central nervous system of rats. J Neurochem 30:187-190

Osnes JB, Hermansen L (1972) Acid-base balance after maximal exercise of short duration. J Appl Physiol 32:59-63

Price M, Moss P (2007) The effects of work:rest duration on physiological and perceptual responses during intermittent exercise and performance. J Sports Sci 25:1613-1621

Reid MB (2008) Free radicals and muscle fatigue: of ROS, canaries and the IOC. Free Radic Biol Med 44:169-179

Sale C, Saunders B, Harris RC (2010) Effect of beta-alanine supplementation on muscle carnosine concentrations and exercise performance. Amino Acids 39:321-333

Sale C, Saunders B, Hudson S, Wise JA, Harris RC, Sunderland CD (2011) Effect of $\beta$-alanine plus sodium bicarbonate on highintensity cycling capacity. Med Sci Sports Exerc 43:1972-1978

Severin SE, Kirzon MV, Kaftanova TM (1953) Effect of carnosine and anserine on action of isolated frog muscles. Dokl Akad Nauk SSSR 91:691-701

Skaper SD, Das S, Marshall FD (1973) Some properties of a homocarnosine-carnosine synthetase isolated from rat brain. J Neurochem 21:1429-1445

Smith AE, Walter AA, Graef JL, Kendall KL, Moon JR, Lockwood CM, Fukuda DH, Beck TW, Cramer JT, Stout JR (2009a) Effects of $\beta$-alanine supplementation and high intensity interval training on endurance performance and body composition in men; a double blind trial. J Int Soc Sports Nutr 6:5

Smith AE, Moon JR, Kendall KL, Graef JL, Lockwood CM, Walter AA, Beck TW, Cramer JT, Stout JR (2009b) The effect of $\beta$-alanine supplementation and high-intensity interval training on neuromuscular fatigue and muscle function. Eur J Appl Physiol 105:357-363
Spriet LL, Lindinger MI, McKelvie RS, Heigenhauser GJF, Jones NL (1989) Muscle glycogenolysis and $\mathrm{H}^{+}$concentration during maximal intermittent cycling. J Appl Physiol 66:8-13

Stellingwerff $\mathrm{T}$, Anwander $\mathrm{H}$, Egger A, Buehler $\mathrm{T}$, Kreis $\mathrm{R}$, Decombaz J, Boesch C Effect of two $\beta$-alanine dosing protocols on muscle carnosine synthesis and washout. Amino Acids (In Press)

Stout JR, Cramer JT, Mielke M, O'Kroy J, Torok DJ, Zoeller RF (2006) Effects of twenty-eight days of beta-alanine and creatine monohydrate supplementation on the physical working capacity at neuromuscular fatigue threshold. J Strength Cond Res 20: 928-931

Stout JR, Cramer JT, Zoeller RF, Torok DJ, Costa P, Hoffman JR, Harris RC, O'Kroy J (2007) Effects of $\beta$-alanine supplementation on the onset of neuromuscular fatigue and ventilator threshold in women. Amino Acids 32:381-386

Stout JR, Graves BS, Smith AE, Hartman MJ, Cramer JT, Beck TW, Harris RC (2008) The effect of beta-alanine supplementation on neuromuscular fatigue in elderly (55-92 years): a double-blind randomized study. J Int Soc Sports Nutr 5:21

Suzuki Y, Ito O, Mukai N, Takahashi H, Takamatsu K (2002) High; levels of skeletal muscle carnosine contributes to the latter half of exercise performance during maximal cycle ergometer sprinting. Jpn J Physiol 52:199-205

Sweeney KM, Wright GA, Brice AG, Doberstein ST (2010) The effects of $\beta$-alanine supplementation on power performance during repeated sprint activity. J Strength Cond Res 24:79-87

Thomas L (1997) Retrospective power analysis. Conserv Biol 11: 276-280

Thomas JR, French KE (1986) The use of meta-analysis in exercise and sport: A tutorial. Res Q Exerc Sport 57:196-204

Trivedi B, Daniforth WH (1966) Effect of $\mathrm{pH}$ on the kinetics of frog muscle phosphofructokinase. J Biol Chem 241:4110-4112

Van Thienen R, Van Proeyen K, Vanden Eynde B, Puype J, Lefere T, Hespel $\mathrm{P}$ (2009) $\beta$-alanine improves sprint performance in endurance cycling. Med Sci Sports Exerc 41:898-903

Walter AA, Smith AE, Kendall KL, Stout JR, Cramer JT (2010) Six weeks of high-intensity interval training with and without $\beta$-alanine supplementation for improving cardiovascular fitness in women. J Strength Cond Res 24:1199-1207

Watson P, Shirreffs SM, Maughan RJ (2004) The effect of acute branched chain amino acid supplementation on prolonged exercise capacity in a warm environment. Eur J Appl Physiol 93: 306-314

Zoeller RF, Stout JR, O'Kroy J, Torok D, Mielke M (2007) Effects of 28 days of beta-alanine and creatine monohydrate supplementation on aerobic power, ventilator and lactate thresholds and time to exhaustion. Amino Acids 33:505-510 